\title{
Management of Cervical Fibroids in Perimenopausal and Postmenopausal Females
}

\author{
Dr. Mukti S. Harne, Dr S. K. Rath, Dr. G.S. Aher \\ Padmashree Dr. Vikhe Patil Medical College, Ahmednagar, Maharashtra, India
}

\begin{abstract}
Aim: Study on cervical fibroids in perimenopausal and postmenopausal females and their management. Material and method: Hereby presenting 4 cases of cervical fibroids in perimenopausal and postmenopausal period, coming to Gynaecology OPD of PDVVPF medical college, Ahmednagar with different clinical presentations. These cases have been diagnosed and differentiated from other organic diseases which were confirmed on histopathology result. Result: No significant factors were found. A tentative reasoning could be the oestrogen spurt that is seen in perimenopausal female. Though the histopathological results were insignificant, still sacromatous changes are a constant threat. Conclusion: These cases were assembled to consider the diagnosis of cervical fibroids even in postmenopausal patients in hypo estrogenic milieu. Etiological factors were considered with history as the source of information. Surgical management was the most appropriate approach in these cases and intraoperative findings confirmed the preoperative diagnosis.
\end{abstract}

Keywords: cervical fibroids, perimenopausal age, postmenopausal age, gynecology, surgical skills

\section{Introduction}

Fibroids are one of the most common gynecological pathologies faced amongst Indian population. The occurrence of fibroids decrease with age and so are least present in the postmenopausal age group. We, in our esteemed college found such cases and were hence were documented.

As most of the leiomyomas are situated in the body of the uterus, there are few which are also present in the cervix and usually to the supravaginal portion which have low incidence in their occurrence. A cervical leiomyoma is commonly single and may be either interstitial or subserous. Rarely it becomes submucous and polypoidal. They are responsible for majority of the operatives in the field of gynaecology nearly about 1/3rd of hospital admissions. Growth of leiomyoma occur in a hyper estrogenic state and thrive maximum during the period of greatest ovarian activity. ${ }^{1}$ Continuous oestrogen secretion , especially when uninterrupted by pregnancy/and lactation is thought to be the most important risk factor in development of myomata. As per the age the size of the liomyoma also regresses, mainly depending on the diminished oestrogenic state.Cervical fibroids develop in the wall of cervix. ${ }^{2}$ The cervix being a mouldable structure the tumour changes the size according to it. Large cervical fibroids are known to show pressure symptoms on the urethras as well as rectum hence leading to change in the shape of the cervix or might even lengthen it. Large cervical fibroids are difficult to handle and need an expert hand to operate these cases ${ }^{1}$.

There are various signs and symptoms of fibroid, most common being heavy menstrual bleeding. ${ }^{3}$ Other symptoms include abdominal pain or pressure, changes in bladder and bowel patterns and, in some cases, infertility. Heavy menstrual bleeding (menorrhagia) may involve flooding (a sudden gush of blood), long periods or passing large clots of blood. ${ }^{4}$ Heavy bleeding is not always due to fibroids, but when it is, it is usually associated with fibroids that grow into the womb (submucous). ${ }^{5}$ Many causes for submucosal fibroid causing bleeding have been enumerated. Most common cause is by increase of the endometrial lining of uterus ${ }^{5}$.

Hereby presenting 4 cases of cervical fibroids in perimenopausal and postmenopausal period, coming to Gynaecology OPD of PDVVPF medical college, Ahmednagar with different clinical presentations.

Case 1:

A 58 years P5L5, postmenopausal woman with complaints of vaginal bleeding since one month and complaints of difficulty and straining during defecation. On general examination patient was alright. Per speculum examination: $4 * 4 \mathrm{~cm}$ mass was seen coming out of the cervix. Bimanual examination: per speculum findings confirmed, origin of the mass could not be trace.

MRI: $10 * 9 * 7 \mathrm{~cm}$ mass in the pouch of douglas, attached to the uterus. USG scan: decreased vascularity on Doppler, uterus was atrophied.

Intraoperative: huge cervical fibroid $8 * 8 * 7 \mathrm{~cm}$ was found attacked to the urterus, displacing the cervix posteriorly and placing itself in the pouch of douglas. 


\section{International Journal of Science and Research (IJSR) \\ ISSN (Online): 2319-7064}

Index Copernicus Value (2013): 6.14 | Impact Factor (2015): 6.391

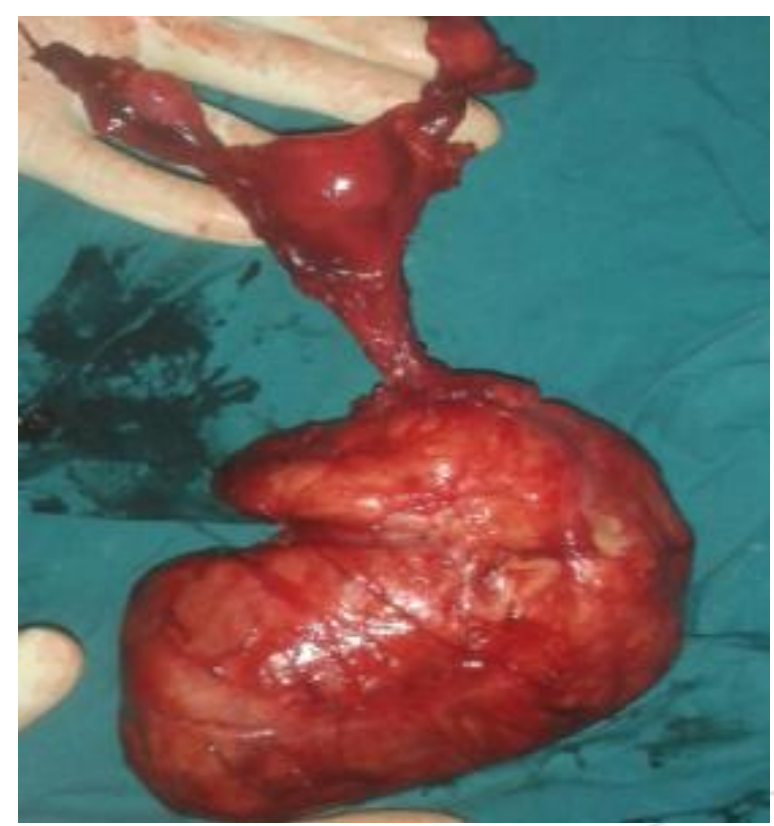

Case 2:

A 68 years old, P4L4, postmenopausal woman with complaints of something coming out of vagina since 6 months and intermittent per vaginal spotting since 6 months. Per speculum examination: $4 * 3 \mathrm{~cm}$ mass coming out of the cervix with uterine sound could be easily passed around it. Congestion present. Bimanual examination: per speculum findings confirmed, uterine size around 6 weeks.

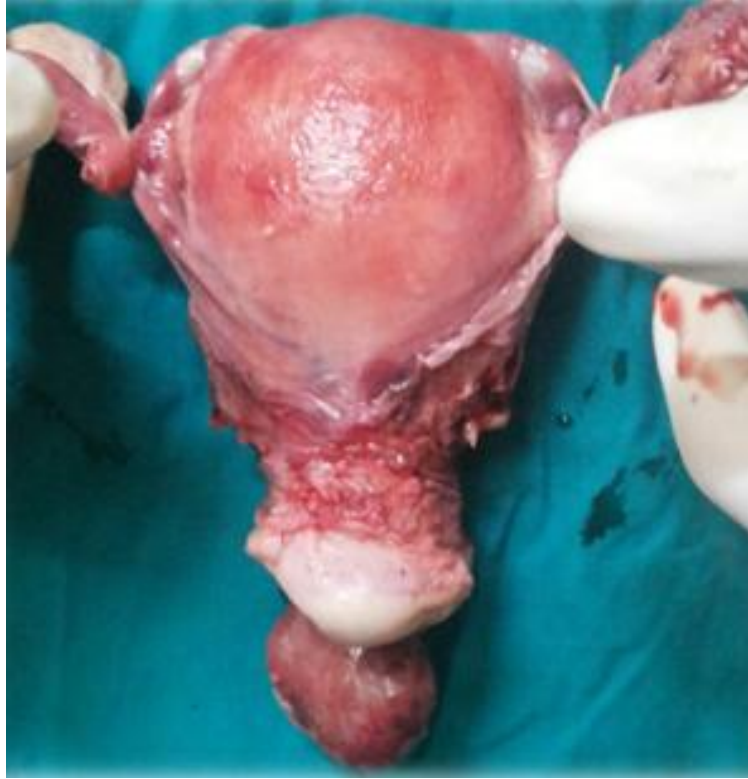

margins were regular. Lower margin could not be reached. Per speculum examination:

A cervical rim could be appreciated. The mass could be visualized through it. Bimanual examination: mass was extremely vascular so bled profusely on touch.

\section{Preoperative:}
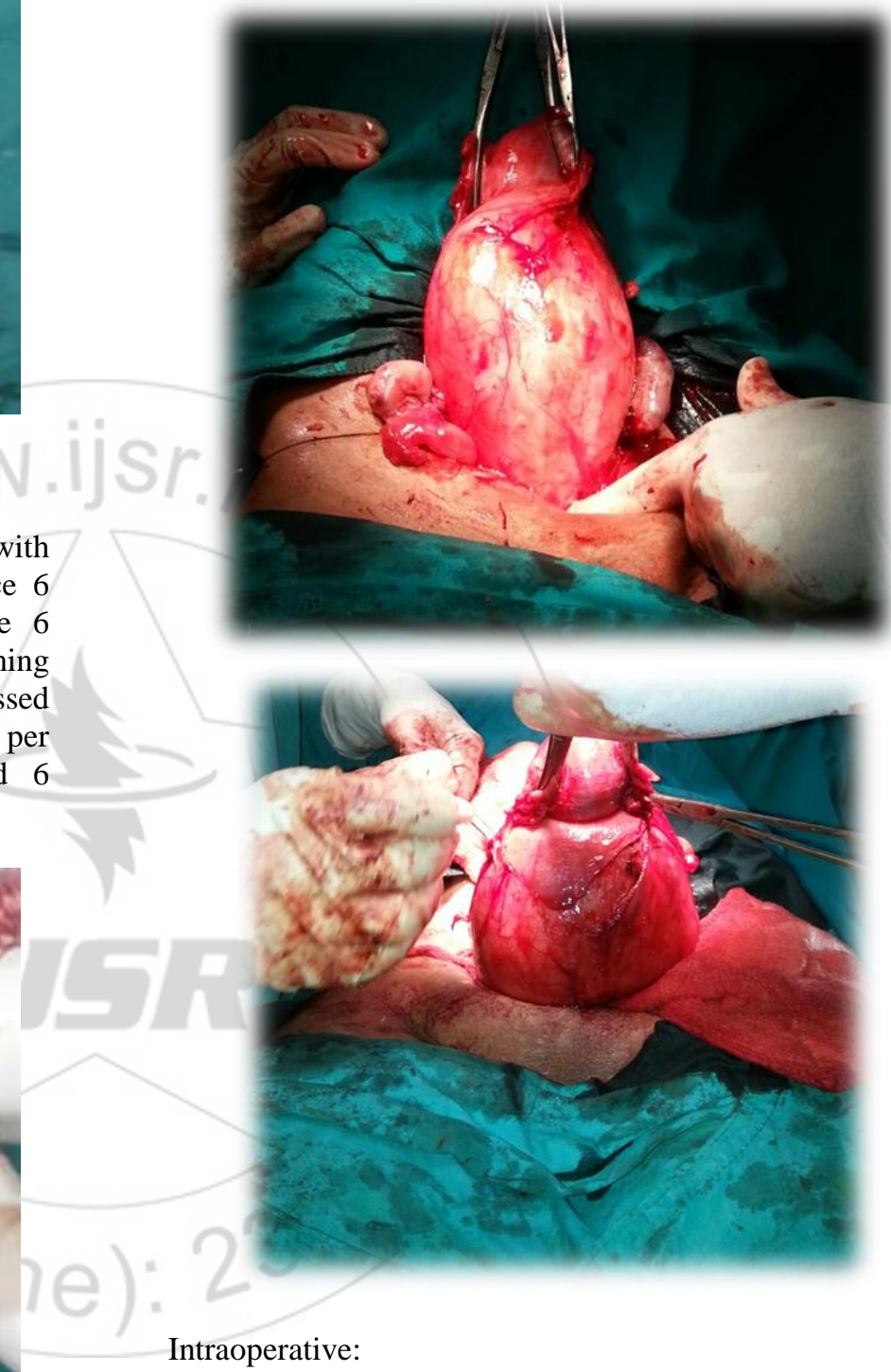

Total abdominal hysterectomy was done. Ovaries were healthy so preserved.

Postoperative specimen delivered:

Intraoperatively: Abdominal hysterectomy and bilateral salpingo oopherectomy was performed.

Case 3:

A 36 years old, P3L3, with complaints of excessive per vaginal bleeding during menstruation since 6 months and increased frequency of menstruation since 6 months. Per abdomen examination: a mass around 16 weeks. Mobility minimally restricted. Mass was firm in consistency and 


\section{International Journal of Science and Research (IJSR) \\ ISSN (Online): 2319-7064}

Index Copernicus Value (2013): 6.14 | Impact Factor (2015): 6.391

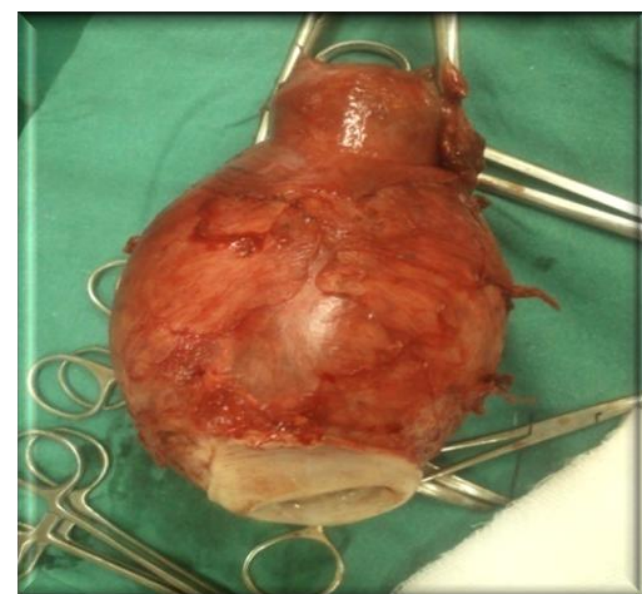

Case 4:

A 52 years old, P4L4, postmenopausal woman with complaints of something coming out of vagina since 1 year. Per speculum examination: $6 * 4 \mathrm{~cm}$ mass coming out of the cervix with uterine sound could be passed around the mass. Bimanual examination: per speculum findings confirmed. Mass was fragile, bled on touch. Uterus could not be felt separately.

Intraoperative: total abdominal hysterectomy with bilateral salpingo opherectomy done.

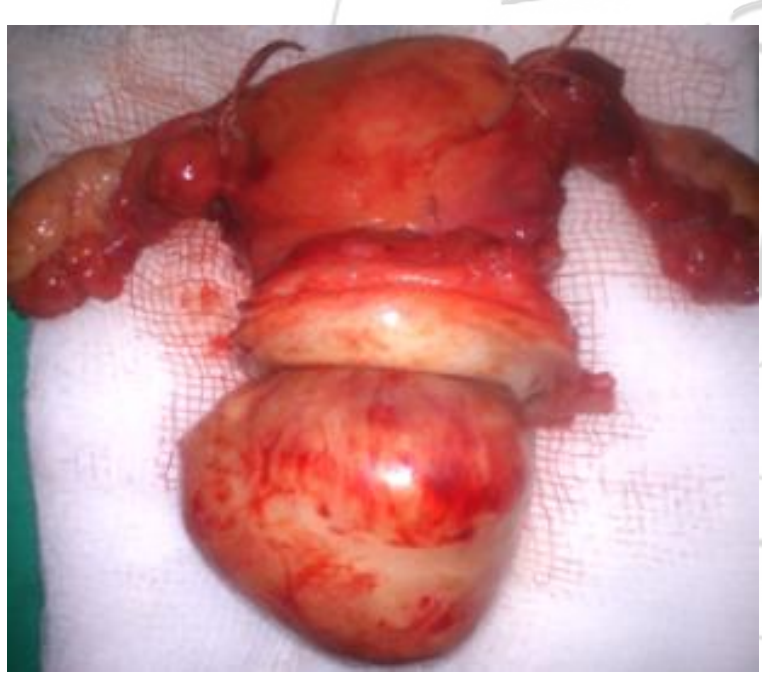

\section{Discussion}

Uterine myoma is the most common benign indication of hysterectomy. There are rare cases of isolated fibromyoma in cervix with intact uterus. Cervical fibroids with excessive growth are uncommon. Such fibroids generally don't affect women's ability to become pregnant though these found with pregnancy are rare. These fibroids are grossly and histopathalogically identical to those found in the corpus. Fibroids with excessive growth may cause pressure symptoms. Treatment of cervical fibroid is either hysterectomy or myomectomy ${ }^{3}$ They may give rise to greater surgical difficulty by virtue of relative inaccessibility and close proximity to bladder and ureters

\section{Conclusion}

Cervical fibroids give rise to greater surgical difficulty by virtue of their relative inaccessibility and close proximity to the bladder and ureters. Hence expertise surgeons are required to attempt such cases.

\section{Results}

No significant factors were found. A tentative reasoning could be the oestrogen spurt that is seen in perimenopausal female. Though the histopathological results were insignificant, still sacromatous changes are a constant threat.

\section{Summary}

\begin{tabular}{|c|c|c|c|c|}
\hline $\begin{array}{c}\text { Case } \\
\text { No }\end{array}$ & $\begin{array}{c}\text { Menstrual } \\
\text { Pattern }\end{array}$ & Complaints & $\begin{array}{l}\text { Size Of } \\
\text { Tumour }\end{array}$ & Surgery \\
\hline 1 & Postmenopausal & $\begin{array}{l}\text { Postmenopausal } \\
\text { PV bleeding, } \\
\text { pressure } \\
\text { symptoms }\end{array}$ & $\begin{array}{c}8 * 8 * 6 \\
\mathrm{~cm}\end{array}$ & $\begin{array}{l}\text { TAH } \\
\text { with } \\
\text { BSO }\end{array}$ \\
\hline 2 & Postmenopausal & $\begin{array}{c}\text { Something } \\
\text { coming out of } \\
\text { vagina, } \\
\text { intermittent PV } \\
\text { spotting } \\
\end{array}$ & $\begin{array}{c}4 * 3 \\
\mathrm{~cm}\end{array}$ & $\begin{array}{l}\text { TAH } \\
\text { with } \\
\text { BSO }\end{array}$ \\
\hline 3 & menstruating & polymenorrhagia & $\begin{array}{c}10 * 8 * \\
6 \mathrm{~cm} \\
\end{array}$ & TAH \\
\hline 4 & postmenopausal & $\begin{array}{c}\text { Something } \\
\text { coming out of } \\
\text { vagina }\end{array}$ & $\begin{array}{l}6 * 4 \\
\mathrm{~cm}\end{array}$ & $\begin{array}{l}\text { TAH } \\
\text { with } \\
\text { BSO }\end{array}$ \\
\hline
\end{tabular}

[1] Kshirsagar SN, MM Laddad: Unusual Presentation of Cervical Fibroid: Two Case Reports. International Journal of Gynae plastic Surgery, 2011; 3(1):38-39.

[2] Tiltman A J: Leiomyoma of uterine cervix: A study of Frequency. International Journal of Gynecology, 2002; 17(3):231-234.

[3] Basnet N, Banerjee B, Badani U, Tiwari A, Raina A, Pokharel H, Yadav P, Agrawal A, Chhetri S B. P. Koirala Institute of Health Sciences: An unusual presentation of huge cervical fibroid; Kathmandu University Medical Journal (2005) Vol. 3, No. 2, Issue 10, 173-174

[4] Jeffcoate N. Tumors of corpus uteri. In. Batla N(ed). Jeffcoate's Principles of Gynaecology, 6thedn. Delhi, Arnold Publication 2010, 466 - 497.

[5] Huge cervical fibroid: Unsuual presentation, Kaur A.P. etal. The Journal of Obstetrics \& Gynaecology of India 2006, Jan-Feb; 52(1) 164 